\title{
Mineral Analyses of Extraterrestrial Metal
}

\author{
J. I. Goldstein ${ }^{1}$, P. G. Kotula ${ }^{2}$, J. R. Michael ${ }^{2}$, and G. R. Huss ${ }^{3}$
}

1. Department of Mechanical and Industrial Engineering, University of Massachusetts, Amherst, MA 01003

2. Materials Characterization Department, Sandia National Laboratories, PO Box 5800, MS 0886, Albuquerque, NM 87185

3. HIGP, University of Hawai' ‘i at Mānoa, Honolulu, HI, 96822

Metal is observed in almost all types of meteorites (irons, stony-irons, and stony) and in lunar soils. The metal contains $\mathrm{Fe}$ with varying amounts of $\mathrm{Ni}(\sim 5$ to $50 \mathrm{wt} \%)$ and minor amounts of $\mathrm{Co}, \mathrm{P}, \mathrm{S}$, and $\mathrm{C}$. Groups of iron meteorites, classified by their trace element contents, are thought to crystallize in the cores of asteroids (protoplanets) while other groups of meteorites crystallize in the silicate in the outer portion of such bodies [1]. The cooling rates of the iron meteorites in the temperature range 500 to $600^{\circ} \mathrm{C}$ vary greatly from $>10,000$ to $<1{ }^{\circ} \mathrm{C} /$ million years $\left({ }^{\circ} \mathrm{C} / \mathrm{My}\right)$. These slow cooling rates allow for phase transformations to take place which cannot be duplicated in the laboratory and should approach equilibrium. The objective of this paper is to show how advanced instrumentation is used to characterize the minerals that form from these transformations.

Fig. 1 shows the Fe-Ni phase diagram. A typical iron meteorite of $10 \mathrm{wt} \% \mathrm{Ni}$ will cool as a single crystal from fcc taenite into the bcc kamacite $(\alpha)+$ taenite $(\gamma)$ phase field around $700^{\circ} \mathrm{C}$ forming a Widmanstatten pattern (Fig. 2). As cooling proceeds, a Ni gradient develops in the taenite as Ni moves into the host phase from the growing kamacite. At lower temperatures, the remaining taenite transforms through a martensite reaction to a two phase assemblage of $\alpha+\gamma$ called plessite and high Ni taenite transforms by a spinoidal reaction to a two phase assemblage of fcc $\gamma$ " and $\gamma_{1}$ (cloudy zone). Fig. 3a shows a fcc EBSD map of the Carlton meteorite in which the high Ni rim of the $\gamma$ and the taenite in the plessite have the same orientation as the parent taenite single crystal. Orientation maps (Fig 3b) confirm that the orientation of the bcc phase to the fcc phase is Kurdjumov Sachs [2] ,(110) bcc // (111) fcc.

Thin foils of IVA irons were prepared for TEM using dual beam FEI DB-235 focused ion beam (FIB) instruments. Selected $\alpha / \gamma$ interface regions were analyzed using a FEI Tecnai F30ST field emission transmission - analytical electron microscope (TEM-AEM) at Sandia National Laboratories. Fig. 4 shows the Ni gradient in the taenite phase close to the kamacite-taenite boundary in Carlton obtained using high resolution $\mathrm{x}$-ray microanalysis. The high $\mathrm{Ni}$ region varies from about $55 \mathrm{wt} \% \mathrm{Ni}$ to about 40 wt $\% \mathrm{Ni}$. A two phase structure is observed in the Ni x-ray map (Fig 4b) at lower Ni contents. Below 40 wt $\% \mathrm{Ni}$, a spinodal structure (fcc $\gamma$ " and $\gamma_{1}$ (cloudy zone) with the high $\mathrm{Ni}(\sim 50 \mathrm{wt} \%) \gamma$ ' as the round phase and the low $\mathrm{Ni}(\sim 5 \mathrm{wt} \%) \gamma_{1}$ as the matrix phase) has formed. Measurements of the Ni gradient in taenite, microns beyond the $\alpha-y$ interface, allow for the measurement of the cooling rate of the Carlton meteorite, between 8 and $45^{\circ} \mathrm{C} / \mathrm{My}$ [3]. The Carlton iron also contains significant $\mathrm{C}>0.2 \mathrm{wt} \%$, and $(\mathrm{Fe}-$ $\mathrm{Ni})_{3} \mathrm{C}$ and $(\mathrm{Fe}-\mathrm{Ni})_{23} \mathrm{C}_{6}$ form on cooling. $\mathrm{C}$ is also distributed between kamacite and taenite. We used a Cameca IMS 1280 ion probe with a $\mathrm{Cs}+$ primary beam to measure the $\mathrm{C}$ content. The spatial resolution is $5-7 \mu \mathrm{m}$ and the $\mathrm{C}$ detection limit is about $1 \mathrm{ppm}, .0001 \mathrm{wt} \%$. Carlton contains $12 \pm 4 \mathrm{ppm} \mathrm{C}$ in kamacite and 330 to $400 \mathrm{ppm} \mathrm{C}$ in the high Ni taenite region. Equilibration from high temperature to at least $400^{\circ} \mathrm{C}$ is confirmed. Mineral analysis at $1-2 \mathrm{~nm}$ spatial resolution using the TEM-AEM remains challenging due to the difficulty of making very thin specimens, $<25 \mathrm{~nm}$. 


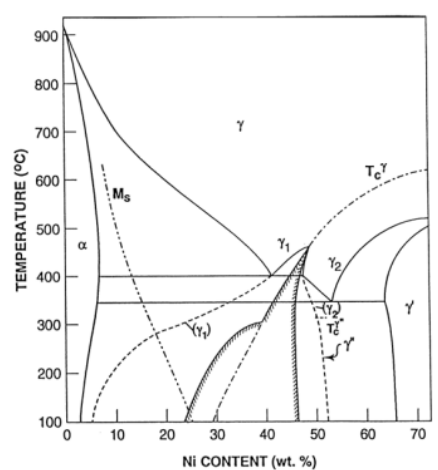

Fig 1. Fe-Ni Phase Diagram Kamacite $-\alpha$, Taenite $-\gamma$ Dashed line is the spinodal

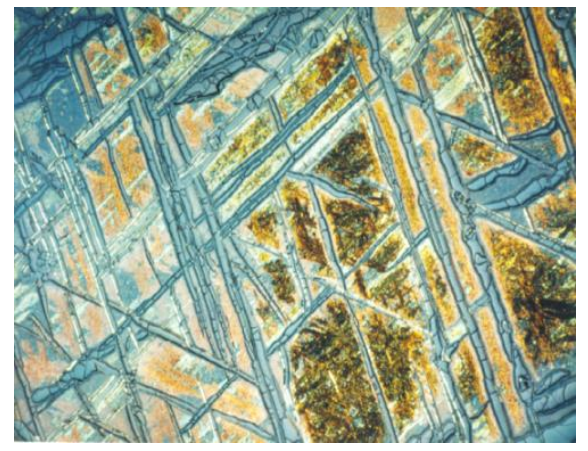

Fig. 2 Carlton iron meteorite Widmanstatten pattern [1]. Kamacite plates are blue.

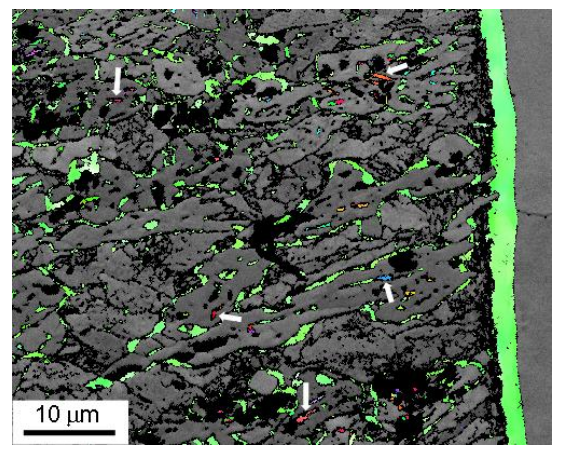

Fig. 3a EBSD fcc orientation map of Carlton. Green regions have the same orientation as the $\gamma$ parent single crystal [2]
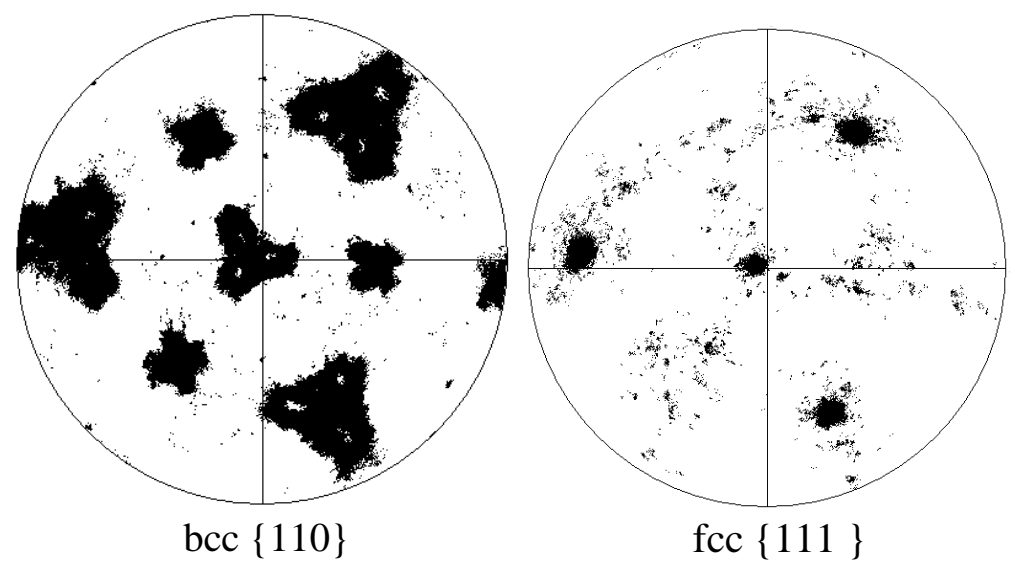

Fig. 3b. Pole figures obtained from EBSD map, Fig 3a

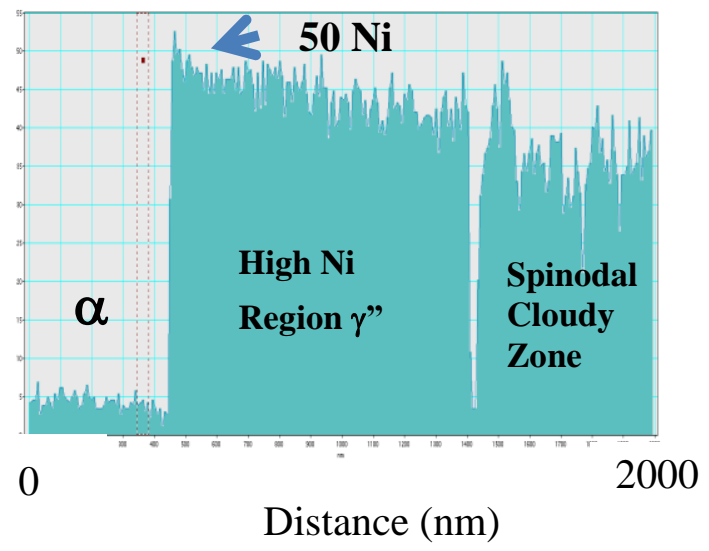

Fig. 4a Ni concentration vs. distance of the outer taenite rim of the Carlton meteorite

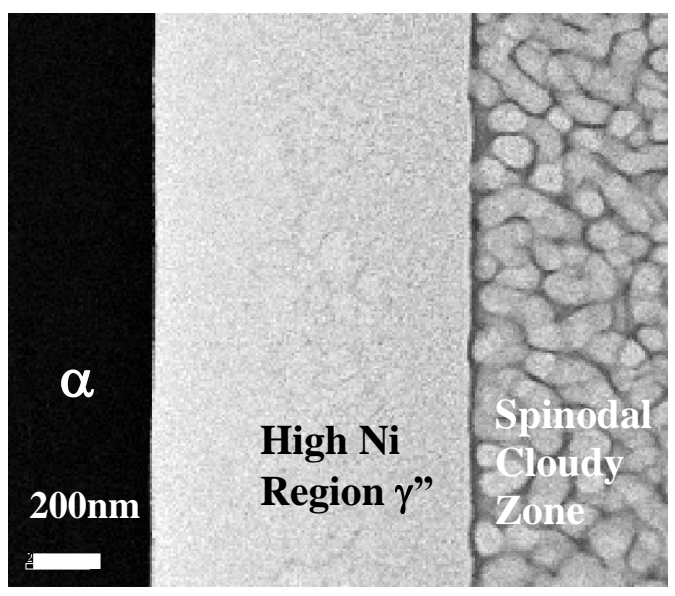

Fig 4b. $2 \times 2 \mu \mathrm{m} \mathrm{Ni} \mathrm{x-ray} \mathrm{map} \mathrm{of} \mathrm{the} \mathrm{outer}$ taenite rim of the Carlton meteorite.

\section{References}

[1] JI Goldstein et al., Chemie der Erde, 69 (2009) p.293

[2] JI Goldstein and JR Michael, Met. Planet. Sci., 41 (2006) p. 553

[3] JI Goldstein et al., Geochem. Cosmochem. Acta., submitted (2014)

[4] This research was supported by NASA cosmochemistry grant NNX11AF62G. Sandia is a multiprogram laboratory operated by Sandia Coportation, a Lockeed Martin Company, for the US Department of Energy (DOE) under contract DEAC0494AL85000. 